\title{
As Inquietações DannunZianas
}

\author{
Fernanda Gerbis Fellipe Lacerda* \\ Flora de Paoli Faria * *
}

RESUMO: A vasta produção de Gabriele D'Annunzio demonstra de forma inequívoca sua consistente erudição e, portanto, não seria um exagero afirmar que atinge sua plenitude ao se dedicar ao teatro. Suas peças negam o drama burguês e verista em voga no final do século XIX propondo a criação de grandes mitos trágicos modernos, inspirados no teatro grego, na filosofia de Friedrich Nietzsche e na Poética de Aristóteles. O Vate ansiava recuperar e reinventar o espírito do teatro trágico e o fez com uma linguagem moderna, nem sempre compreendida pelo público da época. Também os diversos espaços físicos e sociais frequentados por D’Annunzio se fazem presentes em todas as suas produções, transformando sua vida em verdadeira inspiração para suas criações, e sua experiência de vida em obra de arte, criando, assim, um cenário propício para sua existência e como resposta para suas inquietações, que irão se concretizar, de forma plena, na cena teatral.

PALAVRAS-CHAVE: Gabriele D’Annunzio; ethos; teatro italiano.

ABSTRACT: La vasta produzione di Gabriele D'Annunzio dimostra in modo inequivoco la sua consistente erudizione e dunque non sarebbe esagerazione asserire che tocca la sua plenitudine nel dedicarsi al suo teatro. Le sue opere negano il dramma borghese e verista in voga alla fine dell'Ottocento, e propongono la creazione di grandi miti tragici moderni, che si ispirano al teatro greco, alla filosofia di Friedrich Nietzsche e alla Poetica di Aristotele. Il Vate anelava recuperare e reinventare lo spirito del teatro tragico e lo fece con un linguaggio moderno, non sempre compreso dal pubblico coevo. Anche $i$ diversi spazi fisici e sociali frequentati da D'Annunzio si fanno presenti in tutte le produzioni, trasformando la propria vita in vera ispirazione per le sue creazioni, e la propria esperienza di vita in opera d'arte, creando così uno scenario propizio alla sua esistenza e come risposta alle sue inquietudini, che si concretizzeranno pienamente sulla scena teatrale.

\footnotetext{
* Universidade Federal do Rio de Janeiro, Rio de Janeiro, RJ (Brasil) - fernandagerbis@globo.com

** Universidade Federal do Rio de Janeiro, Rio de Janeiro, RJ (Brasil) - paolif@terra.com.br
}

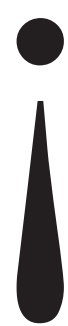


PAROLE CHIAVE: Gabriele D'Annunzio; ethos; teatro italiano.

ABSTRACT: The vast production of Gabriele D'Annunzio shows unambiguously his consistent erudition and, therefore, would not be an exaggeration to say that he reaches his peak when devoting himself to the theater. His plays deny the bourgeois and veristic drama in the late 19th century by proposing the creation of great tragic modern myths, inspired by the Greek theater, by the philosophy of Friedrich Nietzsche, and by the Aristotle'Poetics. The poet yearned to recover and reinvent the spirit of tragic theater, which he did with a modern language, not always understood by the public at the time. The several physical and social spaces frequented by D'Annunzio appear in all of his productions, transforming his life in true inspiration for his creations, and his experience in work of art, thus creating a favorable scenario to his existence and in response to his concerns, which will be real, complete, in the theatrical scene.

KEYWORDS: Gabriele D'Annunzio; ethos; Italian theater. 
Quando o humano acontece poeticamente, então o pensar do ser e seu sentido se dá. O ler poético aconteceu. Manuel Antônio de Castro

poeta Gabriele D’Annunzio nasceu em Pescara, na Itália, na região do Abruzzo. Desde cedo foi incentivado por sua família a apreciar a arte e a leitura de livros clássicos. Conhecia o grego e o latim e estudou em Prato, província de Florença, berço da língua italiana e de poetas e artistas consagrados.

Começou cedo a escrever poesias e, aos onze anos, publicou seu primeiro livro. Desde esse momento, D’Annunzio transitou por diversas áreas literárias e sociais. A vida, para o poeta, era 
a verdadeira inspiração para suas criações, e a necessidade de ser visto e lido era forte e intensa. D’Annunzio escreveu poesias, romances, novelas, discursos políticos, artigos de jornal, peças teatrais e roteiros de filme. Não era um poeta recluso, muito pelo contrário, sua vida social e amorosa era instrumento necessário e inspirador para sua obra. Fazia de sua vida, então, uma verdadeira obra de arte e tinha por necessidade viver entre ela.

A obra de arte dannunziana surge, portanto, da vontade do poeta de responder suas próprias questões vividas. Na opinião de Manuel de Castro (2015b, p.304),

ser, pensar, dizer/narrar, fazer, serão o mesmo. Então a arte e as obras-de-arte serão originariamente o mesmo que ser "e" pensar/dizer, porque essa é a essência do humano em sua humanidade. Ao ser humano caberá interpretá-las interpretando-se e dialogando-se.

Segundo Bàrbieri Squarotti (1993), ao se estudar a vida do poeta italiano, é necessário considerar as frequentes interpretações que associam vida e obra, uma vez que, sem essa perspectiva, obter-se-ia uma análise vazia. Squarotti (1993, p. 13) ainda afirma, nesse viés, que a vida de D'Annunzio foi sempre vista a partir de dois pontos: por um lado, o mito do viver inimitável e, por outro, a separação completa de sua biografia de sua obra.

Faria acrescenta que

a versatilidade da pena dannunziana desconcerta, até hoje, grande parte da crítica italiana, que muitas vezes insiste em abordar a obra do autor abrucês através de fatos ligados unicamente a sua aventurosa vida, repleta de amores, viagens e dívidas, culminando com a construção de sua casa/museu/mausoléu, o Vittoriale, numa colina de Gardone, com uma vista espetacular sobre o Lago de Garda, local onde se encontra com a morte em 1936. (FARIA, 2011, p. 4).

D'Annunzio viveu uma vida que, sozinha, pode oferecer as ocasiões de uma arte igualmente única, inimitável e, principalmente, sempre pronta a se renovar.

A produção artística dannunziana se torna, de fato, plenamente realizada quando ele começa a escrever peças teatrais. É no palco que D'Annunzio consegue unir tudo aquilo que sempre desejou em suas produções: arte, dança, costumes, poesia e sensações. É no teatro, então, que o poeta assume a vida como a essencial experiência da arte. 
Ainda que D'Annunzio seja o poeta decadentista de maior relevo da Itália, ao se observar suas produções, é possível perceber que sua criação estava muito além das características fixas do Decadentismo. A obra poética dannunziana fala por si e representa o desejo e os sentimentos de seu criador, pois

assim são as obras de arte. Nelas devemos distinguir seu aspecto narrativo-técnico, mas jamais reduzir seu poder poético ao seu constituir-se técnico-narrativo. $\mathrm{O}$ poético é a presença vigorante do mítico. Por isso, obra de arte é presença. [...] Será então o acontecer poético. Neste horizonte, as meras narrações de vidas, fatos, personalidades e seus feitos, suas ações, ainda não são obras de arte. (CASTRO, 2015b, p. 293).

Já no âmbito cultural europeu, foi o teatro dramático aquele que melhor se destacou por ser um excelente recurso de comunicabilidade e ter na imitação e na ação seus principais elementos. Esse binômio não possui uma função puramente estética, mas provoca o que teoricamente se denomina "catarse": a instauração de um reconhecimento e de uma identificação afetiva graças aos sentimentos de piedade e terror propostos pelo drama.

D'Annunzio, quando começa a escrever textos para o teatro, nega totalmente o drama burguês e verista, propondo a criação moderna dos grandes mitos trágicos, como em Fedra, e desejando a restauração do teatro grego a partir de seus conhecimentos sobre ele e de outras influências teóricas, que serão aqui apresentadas.

A crítica aponta que ele deu início a sua produção teatral porque buscava o completo aplauso das multidões. O poeta, sem dúvida, amava a glória; entretanto, se quis falar às multidões, foi para comunicar-lhes a beleza e a poesia.

D’Annunzio, então, é atraído para o teatro, porque é no palco, diante do público, através dos gestos e das palavras dos atores que

la materia della vita non era più evocata dai simboli immateriali, ma la vita manifestavasi integra, il verbo facevasi carne, il ritmo si acelerava in una forma respirante e palpitante, l'idea si enunciava nella pienezza della forza e della libertà'. (D’ANNUNZIO, 1995, p. 41).

1 Em tradução livre: A matéria da vida não era mais evocada pelos símbolos imateriais, mas a vida se manifestava integra, o verbo fazia-se carne, o ritmo acelerava em uma forma respirável e palpitante, a ideia se enunciava na plenitude da força e da liberdade. 
Com o objetivo de melhor compreender o teatro dannunziano, é interessante perceber de onde surgiram as inquietações do poeta, ou seja, aquilo que o movia para o caminho da escrita teatral.

Aristóteles (1993, p. 49), na Poética, entende a tragédia como

a imitação de ação séria, completa, que possui certa extensão, numa linguagem tornada agradável mediante cada uma de suas formas em suas partes, empregandose não a narração, mas a interpretação teatral, na qual (os atores), fazendo experimentar a compaixão e o medo, visam à purgação desses sentimentos.

Para Friedrich Nietzsche, em O nascimento da tragédia, ou helenismo e pessimismo, essa catarse pode ser entendida como encantamento, sendo este o pressuposto de toda arte dramática, pois

nesse encantamento o entusiasta dionisíaco se vê a si mesmo como sátiro e como sátiro por sua vez contempla o deus, isto é, em sua metamorfose ele vê fora de si uma nova visão, que é a ultimação apolínea de sua condição. Com essa nova visão o drama está completo. (NIETZSCHE, 2012, p. 57).

Aristóteles não foi leitor de Nietzsche, mas o contrário, sem dúvida, ocorreu e D’Annunzio, com certeza, foi um estudioso de ambos. Ao retomarmos o texto aristotélico, observamos que para o filósofo, a tragédia, pela imitação dos caracteres e das paixões, valendo-se da música, da dança, do espetáculo e, sobretudo, do princípio de verossimilhança, provoca um prazer que lhe é próprio, instigando no ânimo do espectador o terror e a compaixão, ou seja, o pathos.

Staiger (1975) entende que, para os gregos, por muito tempo, não existia a divergência entre gênero lírico e pathos, uma vez que, com frequência, um transformava-se no outro, surgindo uma nova harmonia: a ode. O pathos, então, afirma o autor (STAIGER, 1975, p. 122), seria igual à paixão, pois a fala patética que comove é aquela que mais se aproxima da linguagem lírica.

Já para a era moderna, o gênero lírico só pode ser compreendido quando o outro está aberto a ele, sendo o lírico suave e fluído, afirma Staiger. O pathos é transformado em outro gênero e passa a ocorrer o contrário: é brusco e deve ser aceito quase à força. A fala patética pressupõe algo fora de si. Esse prazer é alcançado com o fim terrível ao qual se destina o personagem trágico. Sempre segundo Staiger (1975, p. 120), é um prazer que vem da vivência da dor por meio da interferência da arte e se compõe de vários elementos. 
Na produção teatral de D'Annunzio, pode-se observar que o autor desejava recuperar e reinventar o espírito do teatro trágico e o faz com uma linguagem moderna. Não existia, no autor, nenhuma vontade de imitação e nem de uma restauração das tragédias gregas, mas, ao contrário, a consciência de que era necessário partir dos gregos para, então, inventar (GIAMMARCO, 2005, p. 122) sua tragédia moderna, uma "nova forma de teatro" que encontraria uma relação entre presente e passado, entre as inquietudes modernas dos personagens dannunzianos e os heróis trágicos.

Como dito anteriormente, D'Annunzio foi leitor do teatro grego. No prefácio de sua tragédia Più che l'amore (1905), declara que sua arte "cammina col suo passo inimitabile, con la movenza che è propria di lei sola, ma sempre sulla vasta via dritta segnata dai monumenti dei poeti padri" (D’ANNUNZIO, 1995, p. 3362). Antonucci (1995, p.2802) elenca quatro razões para o interesse teatral de D'Annunzio:

la lettura della Nascita della tragedia di Nietzsche fra il 1892 e il 1895, il viaggio in Grecia nel Luglio-agosto 1895, l'incontro artístico e poi anche umano con Eleonora Duse dello stesso anno, la tarda [...] eppure significativa conoscenza diretta delle Chorégies d'Orange nell'estate del $1897^{2}$.

O poeta reconheceu nas tragédias gregas a verdadeira fonte trágica e a isso uniu a compreensão de tragédia na leitura de Nietzsche.

Dentre as inúmeras influências está a ideia nietzschiana a respeito da tragédia. Segundo Nietzsche (2012, p. 49), a característica da tragédia é dionisíaca e musical, tendo surgido "do coro trágico e $[\ldots]$ originalmente ela era só coro e nada mais que coro", logo, a música exprime a essência da tragédia, fazendo vibrar a imaginação.

D’Annunzio (2011, p.131), em seu poema Notturno, explica que "la musica è come il sogno del silenzio. [...] La parola che scrivo nel buio, ecco, perde la sua lettera e il suo senso. È musica. Le ore passano. La musica è come il sogno del silenzio" $"$ ".

Nietzsche (2012, p.45) compreende, ainda, que a canção popular se apresenta ao público como o espelho musical do mundo, "como melodia primigênia, que procura agora uma aparência onírica paralela e a exprime na poesia". Dessa maneira, é possível reconhecer que, para o filósofo, a melodia é o que há de primeiro e mais universal - ela pode suportar múltiplas objetivações e, por fim, múltiplos textos. É a melodia, também, aquilo que há de mais importante e necessário na apreciação de um povo, pois,

2 Em tradução livre: “a leitura de O Nascimento da tragédia de Nietzsche entre 1892 e 1895, a viagem à Grécia entre Julho e Agosto de 1895, o encontro artístico e depois amoroso com Eleonora Duse no mesmo ano, o tardio, mas também significativo conhecimento do Chorégies d'Orange, no verão de 1897”.

3 Em tradução livre: “A música é como o sonho do silêncio. (...) A palavra que escrevo na escuridão, exata, perde a sua letra e o seu sentido. É música. As horas pensam. A música é como o sonho do silêncio”. 
de si mesma, a melodia dá à luz a poesia e volta a fazê-lo sempre de novo; é isso e nada mais que a forma estrófica da canção popular nos quer dizer: fenômeno que sempre considerei como assombro, até que finalmente achei esta explicação. (NIETZSCHE, 2012, p. 45).

D’Annunzio depreende das lições de Nietzsche que o trágico, como elemento dionisíaco, estava na música. Faz, então, a união da música com a poesia, sendo uma o complemento da outra. Ele se inspira, portanto, no que Nietzsche (2012, p. 59) escrevia sobre a tragédia:

originalmente a tragédia é só "coro" e não "drama". Mais tarde se faz a tentativa de mostrar o deus como real e de representar em cena [...], como visível aos olhos de cada um, a figura da visão junto com a moldura transfiguradora: com isso começa o "drama" no sentido mais estrito.

Na perspectiva de Antonucci (1995), o escasso sucesso de algumas peças de D’Annunzio se deve, principalmente, ao aspecto inovador de suas criações e à falta de hábito do público com essas novas formas de representação.

Observa-se que o poeta foi único em sua criação no momento em que soube se apropriar de suas influências e produzir seu próprio caminho poético. Todavia, ao trilhar esse seu caminho, nem sempre o outro (espectador, leitor) está pronto para receber aquilo que o poeta deseja transmitir:

A originalidade inaugural de cada sendo se funda no vigorar do ser e de tal modo que não cessando de ser o mesmo, é sempre diferente. Esse é o mistério de toda obra de arte: ser sempre a mesma sendo diferente para cada um que a pensa, lê e relê, sempre tendo como horizonte o acontecer do tempo. Por isso, nenhuma leitura será sempre a mesma (CASTRO, 2015a, p. 280, grifos no original).

D’Annunzio estava além de seu tempo e, por isso, é necessário ler as críticas da época com o entendimento de que, quem as escreveu, talvez não possuísse os meios para a total compreensão de sua obra, isto é, as leituras eram feitas a partir e até onde cada crítico conseguia chegar e enxergar sozinho. Assim, 
para quem escuta sempre há a possibilidade da inaugurabilidade. Toda escuta do acontecer da obra de arte é uma leitura poética. Uma obra de arte nunca se reduz a seu suporte ou forma. Uma obra de arte é sempre presença, fundada no mesmo. (CASTRO, 2015a, p.281-282).

Os personagens dannunzianos também eram inspirados pela obra de Nietzsche, sendo movidos pelo instinto. É claro que, para o poeta que se orgulhava de possuir uma vida superior àquela dos homens comuns, as ideias de Nietzsche respondiam perfeitamente a seus desejos literários. Havia, sem dúvida, certas afinidades entre o temperamento do poeta e o ideal do filósofo: o desejo de domínio, a ambição, a ousadia e a paixão. D’Annunzio sentia tudo intensamente como assim também agia. Não havia lugar para o meio, tudo era forte, violento e com um apreço pelo exagero. Por essa razão, D’Annunzio se afasta da concepção de crime que se encontra nos clássicos gregos cuja finalidade era a nobre afirmação do bem sobre todas as coisas e pessoas.

O herói grego, aquele que praticava o crime, terminava punido e reconhecendo a necessidade de tal punição. Já o herói dannunziano entende que a morte é como um símbolo de purificação, como ocorre com Mila, protagonista de La figlia di Iorio (de 1904), e com San Sebastiano, de Il Martirio di San Sebastiano (de 1910).

Nos textos dannunzianos, o crime é necessário para a expansão e a purificação do indivíduo, enquanto, nos gregos, é a punição do homem o necessário para a vitória do bem. Os heróis gregos agiam pela vontade do destino e os dramas infundiam terror ao público, um terror sagrado, desconhecido. Os espectadores sentiam piedade por esses heróis, vítimas do destino, ausentes de culpa, pois sofriam pelos erros dos antepassados e cujo destino nada mais era que a justiça sobre a terra. Com o público, nesse momento, ocorria a catarse.

Os heróis criados pelo poeta, por outro lado, representam a vitória dos instintos sobre as leis morais e sociais, não havendo, em seus atos, a determinação de uma força superior, como o destino grego. Suas atitudes são espelhadas. Eles desconhecem o destino. A única força que os guia é o instinto. Para D'Annunzio, o homem tem leis próprias, independentes de qualquer poder sobrenatural e de qualquer lei social. Por isso seus personagens representam o instinto humano.

Nesse aspecto, portanto, tais personagens refletem a alma barbárica do poeta, obedecendo aos instintos e aos impulsos, como os homens primitivos. Nenhum herói poderia satisfazê-lo tanto quanto o superuomo de Nietzsche. 
Segundo o filósofo, em Assim falou Zaratustra, o homem vive imerso em um eterno retorno, em um tempo infinito em que todas as situações e os eventos podem se repetir infinitas vezes. Ele se torna escravo desse tempo e absorto em uma dimensão perenemente circular. Nietzsche explica que o mundo é povoado por milhares de pessoas que suportam esse eterno retorno sem tentar mudar seu percurso, ficando presas e refugiadas em regras e seguranças impostas por uma estrutura e pelas próprias convicções. Essas pessoas são incapazes de ver a vida como ela realmente é e se deixam acreditar na lei, na religião, na justiça divina, vivendo, dessa forma, de orgulho, humildade, medos e virtudes, sem nunca tentar sair desse eterno e estático ciclo (NIETZSCHE, 2011, p. 277).

Para Nietzsche, encontrar o caminho que conduz em direção ao super-homem significa conquistar a consciência do próprio ser físico, imerso em um mundo tangível das coisas e, assim, entender que o espírito existe, pois existem as emoções e as compaixões e, principalmente, que somos e que estamos imersos em um mundo onde todas as regras são materiais e, por isso, a palavra e a arte são partes integrantes dessa dimensão material.

Entende o filósofo que o super-homem deva ter a capacidade de se tornar realmente si próprio, conquistando a consciência dos próprios impulsos, entendendo que dentro de si existem forças obscuras que alimentam o próprio ser. Nietzsche toma como exemplo uma árvore, entendendo que há uma dela dentro de cada ser: uma árvore alta e com suas raízes profundas dentro da terra, trazendo, assim, força da escuridão. O super-homem é ciente de seu lado obscuro e o alimenta com o propósito de produzir novas virtudes (NIETZSCHE, 2011, p. 48).

O homem supera a si próprio somente por meio da criação de valores que lhe permitam conquistar uma visão linear do tempo e se libertar do eterno retorno, aceitando o risco de não ser mais compreendido pela gente comum.

O super-homem, desse modo, não é a figura popular, que chama atenção e cujas palavras são perfeitamente compreendidas e aprovadas pela população. Ele muda o mundo, mas o faz longe do povo, distante do clamor e das luzes voltadas para ele, pois isso não lhe pertence. Ele retira da solidão o desejo de falar com uma nova voz, contradiz a si próprio e acredita fielmente na própria força criativa. Para isso, o super-homem deve voltar a ser como a criança que ouve e obedece aos próprios impulsos, indo além de suas razões e naturezas, da moral comum e das regras impostas pelo mundo. A criança, para Nietzsche (2011, p. 55), vive como a folha ou como uma flor, perseguindo o próprio objetivo, além do bem ou do mal.

Posto isso, observa-se, no super-homem dannunziano, traços da filosofia nietzschiana, enquanto outras características correspondem a construções do próprio poeta. Antes de tudo, 
o super-homem dannunziano assume as características do poeta Vate, capaz de encantar os outros, seduzir as mulheres e viver uma vida originalíssima, feita de novos valores, mas, muitas vezes, distante pela pura introspecção. Esses valores se tornam populares, ricos de formas, e possuem uma enorme capacidade de encantar os outros. Esse super-homem retira da força da criança o estupor, alimenta a própria criatividade como um amador de emoções curioso pelo mundo e consagra a arte à própria virtude. O super-homem dannunziano sabe encantar ao criar novos valores baseados no culto do êxtase, na forma e na procura desenfreada por uma nova consciência indiferente à moral comum.

Muitas vezes, em seus textos teatrais, é a mulher que encarna esse personagem de superhomem, talvez pela forte influência e constância com que o poeta relacionava-se com elas. Como exemplo, pode-se citar Fedra (D’ANNUNZIO, 1995). Ela, na versão dannunziana, deseja Ippolito, ainda que ele seja filho de seu marido, e contradiz, dessa forma, todas as regras da sociedade. Declara seu amor diretamente a ele e, uma vez rejeitado, mente e o conduz à morte. Sua intenção é clara: deseja que ele morra para que ela também se mate e, assim, na eternidade, possam ficar juntos. Fedra vai além daquilo que a sociedade determina como o limite, de maneira que seus desejos e vontades tomam as rédeas da situação e são eles que decidem seu destino. Diferentemente dos personagens gregos, a Fedra dannunziana não vê a necessidade de punição, mas vê, na morte, a liberdade para a realização de seus instintos e desejos pessoais.

Se se pensar que, em sua maioria, são as personagens femininas que encarnam esse papel de super-homem, torna-se relevante tecer algumas considerações a respeito da femme fatale.

Essa mulher, que encanta a todos e leva, principalmente, o homem a cometer atos impróprios e, muitas vezes, à morte, já é vista na literatura bíblica, quando, por exemplo, Eva convence Adão a comer o fruto proibido, fazendo que eles sejam expulsos do jardim do Éden para sempre. Há, também, a retomada de outra femme fatale bíblica por Oscar Wilde, na representação de Salomé.

A figura da femme fatale e a de Salomé eram produtos de seu próprio tempo. Suas imagens eram associadas a uma moda exótica que nasceu do desejo de fugir para um mundo distante. A imagem de Salomé, por exemplo, era utilizada como uma metáfora do poder de sedução próprio das mulheres. Em um clima decadente, a figura de Salomé está ligada à exaltação da femme fatale: uma mulher cruel e sedutora que leva à morte um homem (normalmente seu amante), nascida no clima da Belle époque francesa. Já a femme fatale do Decadentismo italiano, nasceu com uma tendência de emancipação, pois é descrita como um ser dominante, mulheres sensuais e desinibidas que desejam uma tempestade de paixão e de luxúria. São figuras, em sua 
maioria e quase sempre, ambíguas. Aparecem como anti-heroínas, colocadas em contraposição às heroínas, sempre boas e angelicais. Fisicamente, são sensuais e possuem olhos firmes, sendo, normalmente, representadas com um grande poder diante dos homens.

Mila, de La figlia di Iorio, e San Sebastiano, de Il Martirio di San Sebastiano, possuem essas características aqui discutidas. Eles são a união do super-homem de Nietzsche e da femme fatale, personagens à altura das ambições de D'Annunzio.

O teatro dannunziano também é repleto de outras influências e é nesse gênero textual que o poeta concilia todo seu conhecimento de arte, ciência, costumes, música, dança e palavra.

Mario Praz reconhece que D'Annunzio apropria-se de numerosas fontes, organizando-as de maneira criativa e inovadora. Praz (1988) questiona que tipo de inspiração teria D’Annunzio, pessoal ou literária, e reconhece que o conhecimento das fontes ajuda a revelar alguns aspectos artísticos da obra literária. Nos textos dannunzianos, afirma Praz (1988, p.387), encontra-se a presença de uma grande influência de outras obras das quais D’Annunzio retira uma ideia, uma palavra ou uma expressão com o objetivo de divulgar exatamente aquilo que é descrito.

Pode-se observar nos textos dannunzianos uma poesia trabalhada, principalmente, no significado da palavra. D’Annunzio apropria-se de palavras e expressões estrangeiras, enriquecendo suas acepções e ampliando seu leque de significações. Um exemplo desse uso encontra-se na palavra fulvo, originalmente uma palavra rara, mas que se tornou comum em sua obra, utilizada várias vezes em suas narrativas e tornando-se um de seus vocábulos preferidos.

Não é por acaso que ele é considerado um artista visual, já que dá cor e imagem à narrativa.

Como o próprio D'Annunzio declara, ele necessitava de fontes de inspiração para fornecerlhe a nota musical, o Lá para a concepção de um fato, de uma rima, de uma frase que ajudasse a compor a narrativa (PRAZ, 1988, p. 412). A riqueza de seu vocabulário se expande para além da literatura, utilizando exemplos de palavras de vários campos semânticos, como o da náutica, da astronomia e da botânica, entre outros. Ele afirmava que o essencial era ter com a palavra um relacionamento tão íntimo capaz de excitá-la para que oferecesse seu significado mais profundo, já que “c'è una sola scienza al mondo, suprema: - la scienza delle parole. Chi conosce questa, conosce tutto; perché tutto esiste solamente per mezzo del Verbo"' (PRAZ, 1988, p. 399).

Quando se pensa que D'Annunzio utilizava um vocabulário muitas vezes específico a um determinado nicho, entende-se o que Guida (2014, p. 185) postula: "as palavras querem o direito à despalavra, mas não como ausência de palavra, e sim como possibilidade de pensá-la fora do âmbito das meras conceitualizações, dos seus usos habituais e repetidos sem serem pensadas".

4 Em tradução livre: "Só existe uma ciência no mundo, suprema: - a ciência da palavra. Quem conhece esta, conhece tudo; porque tudo existe somente por meio do Verbo." 
Compreende-se que, para o poeta, a escolha da palavra era essencial e, por isso, entende-se que estudar as fontes de inspiração dannunziana é deveras importante para a compreensão de sua obra.

D’Annunzio era um poeta inquieto: sua obra reflete essas inquietações e esse desejo de se renovar sempre e seu caminho foi construído a partir de suas questões mais profundas a respeito da arte, da vida e do humano. Para compreender e admirar esse caminho é preciso não só entender sua trajetória, como também se permitir caminhar junto a ele e, assim, ler suas obras sem enquadramentos e julgamentos impostos e predeterminados.

\section{Referências}

ANTONUCCI, G. Introduzione a D'Annunzio drammaturgo. In D'ANNUNZIO, G. Tutto il Teatro. Vol. 1. Roma: Newton Compton, 1995, p. 2798-2806.

ARISTÓTELES. Poética. Trad. Eudoro de Souza. São Paulo: Ars Poetica, 1993.

CASTRO, M. A. de. Época e tempo poético. In Leitura: Questões. Rio de Janeiro: Tempo Brasileiro, 2015a, p.278-283

. História dos sentidos das artes e época. In Leitura: Questões. Rio de Janeiro: Tempo Brasileiro, 2015b, p.284-316

D’ANNUNZIO, G. Fedra. In: D'Annunzio Tutti i romanzi, novelle, poesie, teatro. Org.: Giovanni Antonucci e Gianni Oliva. Milano: Garzanti, 1995, p.3557-3651

. Il fuoco. In: D’Annunzio Tutti i romanzi, novelle, poesie, teatro. Org.: Giovanni Antonucci e Gianni Oliva. Milano: Garzanti, 1995, p.977-1216.

. Il martirio di San Sebastiano. Roma: Elliot, 2013.

. Il Piacere. In: D'Annunzio Tutti i romanzi, novelle, poesie, teatro. Org.: Giovanni Antonucci

e Gianni Oliva. Milano: Garzanti, 1995, p.13-282.

La figlia di Iorio. In: D’Annunzio Tutti i romanzi, novelle, poesie, teatro. Org.: Giovanni Antonucci e Gianni Oliva. Milano: Garzanti, 1995, p.3212-3288.

. Notturno. In: D'Annunzio Tutti i romanzi, novelle, poesie, teatro. Org.: Giovanni Antonucci e Gianni Oliva. Milano: Garzanti, 1995, p.1947-2026.

FARIA, F. de P. As marcas europeias nos saberes decadentistas brasileiros. In Cadernos Neolatinos, Rio de Janeiro: $I V(3)$, set. 2011. http://bit.ly/2hx9L5X Acesso: 5/05/2016.

GIAMMARCO, M. Progettualità e invenzione nel testo di D'Annunzio. Roma: Carocci, 2005.

GUIDA, A. Palavra. In CASTRO, M. A. de (org.). Convite ao pensar. Rio de Janeiro: Tempo Brasileiro, 2014, p. 185-186. 
NIETZSCHE, F. Assim falou Zaratustra. Um livro para todos e para ninguém. Trad. Paulo César de Souza. São Paulo: Companhia das Letras, 2011.

O nascimento da tragédia, ou helenismo e pessimismo. 3. ed. Trad. Jacó Guinsburg. São Paulo: Companhia de Bolso, 2012.

PRAZ, M. D'Annunzio e l'amor sensual della parola. In La carne, la morte e il diavolo. Milano: Mondadori, 1988, p. 399-449.

SQUAROTTI, G. B. Invito alla lettura di D’Annunzio. Milano: Ugo Mursia, 1993.

STAIGER, E. Conceitos fundamentais da poética. Trad. Celeste Aída Galeão. Rio de Janeiro: Tempo Brasileiro, 1975.

Recebido em 15/4/2016

Aprovado em 02/6/2016 